In like vein, I found the coverage of the advocacy role (pages 112-113, 169-170) disappointing since hefty objections to it do exist in the nursing literature. In addition, the consideration of the pros and cons of advance directives (pages 220-221) could be criticised for a legal bias with the moral (and underpinning philosophical) difficulties disappearing from view. Generally though, the balance between the legal and moral commentary is well sustained. Indeed, the above remarks turn out to be rather minor objections to what I consider to be a most informative and readable book for nurses.

It should be noted that the accuracy of the legal material in the book and the credibility of the legal opinions expressed have to be taken on trust as the reviewer has no legal expertise.

LOUISE DE RAEVE Centre for Philosophy and Health Care, University of Wales, Swansea

\section{Ethical foundations of health care. Responsibilities in decision making}

Jane Singleton and Susan McLaren, London, Mosby, 1995, 202 pages, $£ 9.95 \mathrm{pb}$.

This book provides a useful addition to existing texts for health professionals on ethical theory and contemporary health care dilemmas. The greatest strength of the book is its careful structure, which makes it ideally suited to becoming a reference text for student and teacher alike.

Written jointly by a philosopher and a nurse the book enjoys the strength of both perspectives. The volume is divided into two sections. The first explores philosophical frameworks in some detail and the second examines contemporary health care dilemmas.

As might be expected, consequentialist and deontological theories are introduced and the principles of autonomy, beneficence, non-maleficence and justice discussed in the first part of the book. The debate benefits from quotations from primary sources, allowing the reader to capture something of the flavour of the original. The exposition is clear but will take the reader beyond mere introduction to address some complex issues of interest.
The second part of the book reviews questions of life and death, confidentiality, informed consent, truth-telling and health care research. In addition there are some wideranging discussions of contemporary relevance such as access to health care, professional codes of conduct and consumer perspectives. One disappointing omission from the text is any discussion of the ethical issues raised by health promotion. With the exception of a brief reference to paternalism in primary prevention this burgeoning area was left largely unexplored. Given the current emphasis upon health promotion in many curricula for health professionals, including Project 2000 for nursing students, this oversight will need addressing in future editions.

Each chapter of the book begins with some learning outcomes which usefully focus the mind. Clear headings and subheadings enhance the book's value as a teaching tool, as does the numbering system which facilitates cross-referral. Each chapter similarly concludes with some learning exercises, many of which would translate directly into discussion topics or assignment titles for students. In addition there are some useful further reading lists and a summary of key points. The book concludes with some well chosen appendices, including the professional codes or rules for physiotherapists, occupational therapists and nurses.

Two chapters stand out as being of particular value: chapter three, which addresses the question of what critical ethics can achieve and chapter eight where this is re-visited, with a case study of euthanasia. These will be of particular use with enquiring students who may question the value of the whole critical ethics 'enterprise'.

Ethical Foundations of Health Care merits a place in the library of undergraduate and postgraduate students of health care who have an interest in ethics and who seek a well constructed guide to the subject.

\section{ALISON DINES \\ Lecturer, Department of Nursing Studies, \\ King's College, University of London \\ The family in the age of biotechnology}

Edited by Carole Ulanowski, Aldershot, Avebury, 1995, 161 pages, $£ 32.50$ hc.
There is, no doubt, something to be said for philosophy applied to practical affairs, provided that the philosophy be good and that the issues be worth addressing and credibly addressed. Neither qualification is evident everywhere in this collection of papers read at a conference of the Society for Applied Philosophy. Indeed the chapter closest to reality was written, not out of the literature of adversarial ideology, but out of the experience of a social worker with children assigned to foster or adopting parents by order of a court. The papers are exercises in social theorizing; they do not address the ethics of medical practice.

The papers fall roughly into three groups. The first speculates on concepts of family relationship arising from assisted reproduction technology (ART), as regulated, in Britain, by the Human Fertilisation and Embryo Authority. (Editors should get their facts right: the HFEA was established under the statute of 1990, not in the 1980s, when regulation was undertaken by the Voluntary (Interim) Licensing Authority.) Almond, iळ conscious difference from most othe contributors, defends family bonds a the cement of social existence, not subject to construction and destruction by fragile and volatile individual choice. Legal and social acceptance of the 'fractionalization' now read into families formed by ART should await experience and reflection on it. Cole has his own view of the legal controls for ART already in place: they purport to protect the welfare of children; in fact their aim is reactionary, to protect the traditional or 'moral' family and to preserve the privileged and powerful position of men within it.

The second group of chapters meets the Editor's call for 'reflective space' on the family. Thomasson would prefer 'a non-biological ectogenic form of parenting' to nurture in a biological unit. In such a 'networked' family the wise child would not want to know her father; it won' matter. Leighton, with his social worker's knowledge of children, would differ: children, in order to develop their sense of self, need an identifiable human beginning and a family relationally based on integrity, trust and openness. There is no place for the pretence that a bio-engineered child is the natural child of its pseudoparents.

In the third group, on marriage, Wilkinson and Gregory chase the same hare. Wilkinson asks whether 
monogamy is the best way of satisfying basic wants, and concludes that there are positive reasons for abandoning it, at least as a model for personal relationships: we should be openminded in order to allow maximum flexibility and diversity. Gregory whose bibliography lists only his own writings - suggests that, since marriage (sic) must fail, we now move on from sequential to concurrent marriage: we shall then avoid possessiveness and the jealousy generated by the suspicion or sense of being dispossessed. Brecher insists that marriage must have a public meaning, not determined by the intentions and characters of individuals. Hence its political value: marriage furthers a social ideology of ownership (since central to marriage is ownership of women by men); it helps to exclude women from public life; it is the engine of capitalist consumption. Marriage is therefore numbered amongst the 'morality-affecting harms', like 'racism' and 'sexism'. This is but a prolegomenon for a critique of marriage.

The volume does not tell us what philosophers learned from one another in their conference.

G R DUNSTAN Department of Theology, University of Exeter

\section{Death and deliverance. 'Euthanasia' in Germany 1900-1945}

\author{
Michael Burleigh, Cambridge, \\ Cambridge University Press, 1994, \\ 382 pages, $£ 35.00 \mathrm{hb}, £ 14.95 \mathrm{pb}$.
}

Fifty years after the collapse of the Third Reich, one may be forgiven for thinking that the subject of the Nazi policies of extermination had been worked over to exhaustion. The 'Holocaust' and the 'Final Solution' to wipe out the Jewish and other 'inferior' races have dominated attention, leaving some aspects of the subject comparatively neglected. Less attention has been given to attitudes in Germany towards the value of life in the early years of the century, especially in the hard economic climate during and after World War I. Did the Nazi doctrines spring up ready-made or was the seed already present in the German mind before the rise of Hitler? Most particularly, how did the medical profession, which fulfilled a key role in carrying out the policy, come to distort its ethical base so disastrously?

The author, Reader in International History at the London School of Economics, does not deal with the 'Final Solution' ie the 'Holocaust' except very briefly. This is deliberate since he has covered that ground in previous books (Germany Turns Eastwards, 1988 and The Racial State: Germany 1933-1945, 1991) and the book's title makes it clear that 'Euthanasia' is the topic, a policy which predated the 'final solution' and provided the techniques and mental set to accommodate it.

Burleigh begins by showing that the first questioning of the classical concept of euthanasia as a 'fine' or 'gentle' death began in the 1890 s with the concept of a 'life unworthy of life', and alarm at the intolerable economic burden on the state of the incurably ill and mentally defective. During World War I, rations were drastically reduced in mental asylums and mortality soared. Financial cutbacks led to gross overcrowding and understaffing.

In the 1920 s the debate intensified after the publication of Permission for the Destruction of Life Unworthy of Life by Karl Binding, a jurist, and Alfred Hoche, a psychiatrist. Building on a series of unimpeachably liberal premises, the tract systematically rehearsed a series of illiberal and crudely materialistic arguments in favour of involuntary euthanasia, using the economic burden on the state to outweigh the right to life of the individual. There was much criticism and, naturally, the 'slippery slope' argument appeared but the economic argument gained ground, accompanied by the first sinister appearance of crude Darwinism, arguing for sterilisation of those deemed to carry defective traits and the ending of the life of those deemed to be a burden to themselves and, particularly, to the state. They were selected by Hereditary Health Courts, set up to identify individuals for sterilisation or 'euthanasia'. Threeman teams of referees went round asylums selecting cases for transfer to asylums where those selected were deliberately allowed, or helped, to die. By 1938 defective children and Jews were being starved and dying of neglect, gassing or lethal injection in asylums. This was made possible by the poor quality of doctors and nurses in these institutions, the unfavoured rump of their professions, and the introduction of unsuitable staff from outside. After 1936, staffing was restricted to members of the SS.

While there was opposition from some quarters in the professions and from the asylums run by religious organisations, there seems to have been considerable acceptance and collusion and the SS was able to ride rough-shod over all opposition.

In 1939, Hitler formally instructed the implementation of a programme of euthanasia and wrote a note "extending the powers of specific doctors in such a way that, after the most careful assessment of their condition, those suffering from illness deemed to be incurable may be granted a mercy death'. This led to the setting up of 'Aktion T-4' which remained an undercover organisation. The instruction was never enacted in law. The wishes of Hitler were simply indirectly interpreted as orders. Though they claimed that their selections were made with compassion and strict scientific rigour, choice was in fact made on the most haphazard grounds and very soon included the work-shy, trouble-makers and nonAryans. Each asylum was given an increasingly large quota of victims to find. Since there was no legal basis, tho psychiatrists had to provide certificates with fictitious causes of deatho Relatives who questioned why theif loved ones had suddenly died of 'heart failure' or 'pneumonia' received short shrift. Nevertheless, there was widespread alarm in the community and many suspected what was going on, not least because of the pungent smoke that arose from certain asylums which had become collecting centres for the condemned.

Though the churches remained equivocal, Bishop Galen of Münster was a longstanding critic. In 1941 he published a sermon condemning 'euthanasia'. It was widely circulated and the RAF dropped leaflets over Germany quoting it. Though many priests and laymen who repeated what the Bishop said were disciplined or sent to concentration camps, Bishop Galen was threatened but not sacked.

To promote public acceptance of the principle of 'life unworthy of life', films were made. At first these were crude documentaries, intercutting images designed to degrade, criminalise and dehumanise the mentally and physically handicapped in order to justify sterilising them. However, later more sophisticated feature films were made, with story-lines arguing the case for 'euthanasia', but showing a very sanitised version of the actual mechanics of gassing. 